\title{
Raising Capital in an Insurance Oligopoly Market
}

\author{
Julien Hardelin and Sabine Lemoyne de Forges \\ Département d'Économie, École Polytechnique, 91128 Palaiseau Cedex, France and \\ AgroParisTech ENGREF, 19 avenue du Maine, 75732 Paris Cedex 15, France.
}

We consider an oligopoly market where firms offer insurance coverage against a risk characterised by aggregate uncertainty. Firms behave as if they were risk averse for a standard reason of costly external finance. The model consists in a two-stage game where firms choose their internal capital level at stage one and compete on price at stage two. We characterise the subgame perfect Nash equilibria of this game and focus attention on the strategic impact of insurers capital choice. We discuss the model with regard to the insurance industry specificities and regulation. The Geneva Risk and Insurance Review (2012) 37, 83-108. doi:10.1057/grir.2011.4; published online 11 October 2011

Keywords: price competition; risk-averse firms; insurance market; capital choice

\section{Introduction}

Determining the appropriate levels of capital holding and investment in risk management is a major aspect of insurers' and reinsurers' activities, as well as a prominent regulatory issue. Owing to the trend towards consolidation of the last two decades, insurance markets are far from being perfectly competitive. Hence, firms' price and capital decisions can be expected to become strategic variables. In a market where capital choices are crucial issues for insurers and where cycles linking prices and capital are empirically observed, it is particularly important to better understand how capital decisions are impacted by imperfect competition. The purpose of this paper is to study the endogenous choice of capital holding and pricing decisions for an oligopoly of (re)insurance risk-averse firms that face costly external finance. Intuitively, when firms compete strategically in an oligopolistic market, risk management decisions may be distorted by strategic effects. These distortions may in turn affect insurance supply decisions (lines of risks to cover and unit price). More capitalized firms would be able to accept more risks, and so capital holding could increase their market shares on lines of risks that are characterised by high aggregate uncertainty. 
In order to study this issue, we consider the following two-stage game: at the first stage, insurance firms choose their level of internal capital, which determines the firms' cost of risk; at the second stage, they compete on price on the output market. Insurers are assumed to supply coverage against a single line of risks characterised by aggregate uncertainty. The number of insurers is exogenous. As in Wambach, ${ }^{1}$ we obtain a continuum of Nash equilibrium prices at stage 2, allowing for positive oligopolistic rents. Under a stricter assumption of decreasing absolute risk aversion (DARA), we expand this result to asymmetric firms. We find that the first-stage choice of capital is strategic for the firms, as playing safer on the capital market induces a harsher behaviour on the product market. We underline the importance of the cost of capital in the insurance industry outcomes. Finally, we propose a different approach to the question of capital regulation, complementary to the classical solvency argument ${ }^{2}$ required levels of capital may have an impact on competition prices, and thus be beneficial in a social welfare perspective.

Related literature: The literature on insurance economics has highlighted two fundamental reasons for an insurance firm to invest in risk management and costly capital holding. The first one relates to solvency. ${ }^{3}$ Profit-maximizing insurance firms have a rationale to reduce their probability of default because of consumers' concern. The second explanation relies on direct state-contingent costs that make the firms' payoffs become non-linear. ${ }^{4}$ These explanations are not mutually exclusive, and give so many reasons for insurance and reinsurance firms to reinsure themselves, hedge, manage risks, and participate in insurance pools, ${ }^{5}$ as well as to hold internal costly initial capital to reduce the cost of risk. ${ }^{6}$

If such rationales for risk management and capital holding by insurers and reinsurers are well understood (at least theoretically), less is known about the way these decisions operate in the strategic context of imperfect competition. Indeed, insurance markets are usually considered to be competitive. Although this assumption is well documented, there are also arguments in favour of

\footnotetext{
${ }^{1}$ Wambach (1999).

2 Plantin and Rochet, 2007.

${ }^{3}$ Rees et al., 1999; Fagart et al., 2002; Zanjani, 2002.

${ }^{4}$ These non-linearities may include: (i) the presence of convex taxes on corporate earnings, (ii) financial distress costs, and (iii) costly external funds due to costly state verification (Froot et al., 1993; Tirole, 2006; Gollier, 2007). On the contrary, the limited liability of shareholders supports the assumption of risk-loving behavior of firms.

${ }^{5}$ Froot et al., 1993.

${ }^{6}$ Froot, 2007.
} 
imperfect competition as a more appropriate framework in the cases of specialised insurance companies ${ }^{7}$ and the reinsurance sector. ${ }^{8,9}$

Our paper is related to both the oligopoly and finance literatures. In recent years, the oligopoly literature has been extended to the case of risk-averse firms facing different sources of risk (demand, cost, rivals' characteristics). In this vein, Polborn ${ }^{10}$ and Wambach ${ }^{1}$ study an oligopoly of $n$ firms with risk-averse managers, producing a single output with constant but stochastic marginal cost. ${ }^{11}$ In such setting, the authors find that the Bertrand paradox ${ }^{12}$ - that is the fact that at least two competitors are sufficient to restore the competitive price outcome - can be resolved in the sense that there exist Nash price equilibria above the expected marginal cost, which lead to strictly positive oligopolistic rents. Asplund ${ }^{13}$ notes the importance of the initial wealth when firms display DARA. Froot and O'Connell ${ }^{14}$ also introduce imperfect Cournot competition among risk-averse reinsurers that pool insurers with correlated portfolios. They suggest that imperfect competition tends to reinforce the overpricing of correlated risks when compared with the fair price. Because we assume a price competition, our model is closely related to Polborn ${ }^{10}$ and Wambach ${ }^{1}$, with the difference that they do not consider a capital choice stage that takes place before the pricing decision.

Our analysis can also be related to the more general oligopoly literature. Indeed, introducing risk on marginal cost and considering risk-averse firms is quite similar to assuming increasing and convex costs. Price competition with convex cost functions has been studied by Vives ${ }^{15}$ and Weibull ${ }^{16}$ among others. The specificity of our analysis comes from the endogenous shape of the risk premium through capital choices and their wealth effect. Our stage 1 capital choice can be interpreted as a form of technological investment that affects the shape of the cost function, that is the risk premium in our setting. Finally, our two-stage game approach with a capital choice followed by a price decision

\footnotetext{
${ }^{7}$ Nye and Hofflander, 1987.

${ }^{8}$ Gron, 1990.

${ }^{9}$ Moreover, as insurance premiums are partly determined by the prices and capacities of reinsurance market, the degree of competition in the reinsurance sector does matter for the insurance one.

${ }^{10}$ Polborn (1998).

${ }^{11}$ Other markets also have such characteristics: cost of research and development, cost of expertise among others.

12 Tirole, 1988.

${ }_{13}^{13}$ Asplund (2002).

${ }^{14}$ Froot and O'Connell (2008).

${ }^{15}$ Vives (1999).

${ }^{16}$ Weibull (2006).
} 
may recall Kreps and Scheinkman's ${ }^{17}$ setting. Our model is in fact different: although they endogenize the choice of a quantity constraint, we endogenize the choice of the shape of the cost function, measured in monetary terms by the risk premium. ${ }^{18}$

The paper is organised as follows: the next section lays out the competition game; the sections after that derive the results on the impact of capital holding on the competitive structure of the market; the penultimate section looks at the social welfare and capital regulation. The final section discusses these results in line with the insurance industry specificities and concludes.

\section{The model}

\section{The oligopoly market}

We consider an oligopoly of $n$ insurance firms, indexed by $i=1, \ldots, n$, that produce the same non-differentiated single good $q^{i}$ that can be thought of as a quantity of insurance coverage sold to a continuum of risk-averse insureds. Insurers cover a single line of risk, which is characterized by aggregate uncertainty. This aggregate uncertainty may arise from correlated risks across policyholders, a typical feature of natural disaster risks, such as earthquake, drought, etc. ${ }^{19}$ The aggregate demand for coverage is exogenous, nonstochastic, and defined by $Q(p)$ when all insurance companies charge the same price $p . Q(p)$ is continuous, decreasing in $p$ and $\lim _{p \rightarrow+\infty} Q(p)=0$.

Because of the inversion of the production cycle, insurance firms do not know ex-ante the exact cost of supplying such coverage. ${ }^{20}$ Let us denote

${ }^{17}$ Kreps and Scheinkman's (1983).

${ }^{18}$ A third strand of literature that appears to have some connections with our paper is the work analysing the strategic value of debt emission for firms in oligopoly markets (Brander and Lewis, 1986; Wanzenried, 2003). We depart here from this literature as we focus on the impact of risk aversion on the choice of ex-ante equity capital, from the investor's point of view: risk aversion enhances the weight of high cost states, rendering capital level a strategic choice as it modifies the price equilibria.

${ }^{19}$ When risks are statistically independent across policyholders, risk management and capital budgeting decisions are still an issue as the probability of default is never null, but it is clear that the problem becomes more stringent when there is aggregate uncertainty about the expected profit from a line of risk. Alternatively, it may also be interpreted as knightian uncertainty; this is typically characteristic of "new technological risks", for which the probability distribution cannot be derived from past observations.

20 This cost can be approximated by the expected loss plus a loading factor that covers a set of various transaction costs (administrative costs, ambiguity aversion, security margin, and so on). Even in situations where the law of large numbers applies well, the cost of a given insured risk remains fundamentally stochastic. 
$\tilde{L}_{i} \in\left[0, L^{\mathrm{max}}\right]$ the stochastic loss per unit of output (or coverage) $q^{i}$ sold by the firm $i$. We note $\bar{L}_{i}=\mathbf{E} \tilde{L}_{i}$. The profit from exerting the insurance activity is stochastic because of cost uncertainty. For a firm $i$ and a given price $p$, let us define the firm's profit $\tilde{\pi}^{i}\left(p, q^{i}\right)$ as follows:

$$
\tilde{\pi}^{i}\left(p, q^{i}\right)=q^{i}\left(p-\tilde{L}_{i}\right)=q^{i} \tilde{m}_{i},
$$

where $\tilde{m}_{i}=\left(p-\tilde{L}_{i}\right)$ is the stochastic unit margin. When the insurance coverage is fairly priced, that is $p-\bar{L}_{i}=0$ and the insurance activity entails no transaction costs, the firm $i$ 's expected profit is equal to zero, as in the standard competitive model with risk neutral insurers. If, owing to market power, the per unit price is strictly above the expected loss per unit, that is $p-\bar{L}_{i}>0$, then increasing supply $q^{i}$ (via increasing market share) increases the expected profit of the firm, but also makes profit riskier. This is the fundamental trade off that will be at the heart of the following analysis. To keep things simple, we will consider that the losses of all insurance firms are distributed identically: $\forall i, \tilde{L}_{i}=\tilde{L}$.

\section{Firms' objectives}

At the beginning of the game, each firm is endowed with an initial level of capital $w_{0}$ that corresponds to past equity emissions and retained earnings. The (re)insurance company can choose the level of external capital it raises $K_{i}$. This capital is brought by shareholders and does not bring any return during the period. The firm's stochastic final wealth is $\tilde{w}_{f}^{i}=w_{0}^{i}+K_{i}+\left(p_{i}-\tilde{L}\right) q^{i}$. Following Froot et al.'s ${ }^{5}$ representation of the firm, we denote $P\left(\tilde{w}_{f}^{i}\right)$ the value of insurance company $i$ for a stochastic final wealth $\tilde{w}_{f}^{i}, P$ being increasing and concave. This representation, relying on a costly external finance argument, implies that firms behave as if they were risk averse. The insurance firm's objective is to maximise its expected net value:

$$
\mathbf{E} P\left(\tilde{w}_{f}^{i}\right)-(1+\tau) K_{i},
$$

where $(1+\tau)$ represents the opportunity cost of capital for the shareholders, with $\tau \geqslant 0$. This opportunity cost reflects the liquidity constraints to which insurance companies are compelled because of their asset liability management. We consider that firms have an outside option that gives them an expected value equal to $V^{\text {out }} \geqslant 0$, which is assumed exogenous.

We define the risk premium by analogy with the usual definition, ${ }^{21}$ with the difference that the function $P($.$) replaces the standard von Neumann-Morgenstern$

\footnotetext{
${ }^{21}$ Gollier, 2001.
} 
utility function $u($.$) . We denote \bar{w}_{f}^{i}=\mathbf{E} \tilde{w}_{f}^{i}$. The 0 -mean risk to which it is exposed is $(\tilde{L}-\mathbf{E} L) q^{i}$. For notational simplicity, we denote the risk premium $R^{i}\left(\bar{w}_{f}^{i}, q^{i}\right)$ and we have

$$
\mathbf{E} P\left(\tilde{w}_{f}^{i}\right)=P\left[\bar{w}_{f}^{i}-R\left(\bar{w}_{f}^{i}, q^{i}\right)\right] .
$$

We make the following assumptions:

(A1): $P$ is increasing and concave. The pseudo-risk premium has similar characteristics as the standard risk premium. In particular, $R$ is increasing and convex in $q^{i}$.

(A2): $\partial R / \partial W \leqslant 0$ that corresponds to the standard DARA hypothesis.

(A3): For $m \in\{1, \ldots, n\} \quad(d / d p) \mathbf{E} P\left(w^{i}+(p-L) Q(p) / m\right) \geqslant 0$. This states that demand is sufficiently inelastic.

(A4): The profit maximising output of the firms increases when the price increases. (A5): $\Delta R$ decreases in $w$, where

$$
\Delta R=R(w+\bar{\pi}(p, Q(p)), Q(p))-R\left(w+\bar{\pi}\left(p, \frac{Q(p)}{n}\right), \frac{Q(p)}{n}\right)
$$

This assumption, stronger than DARA, is necessary to better characterise the impact of a multiplicative risk. ${ }^{22}$ Prices are in a region were the risk effect is amplified by the wealth effect: the more capitalized firms are less reluctant to serve higher demand and hold more risk.

\section{Timing of the game}

The market equilibrium is modelled as a subgame perfect Nash equilibrium (in short equilibrium) of the following two-stage game:

- Stage 1: Firms choose a level of additional capital $K_{i}$ by issuing new shares (if $K_{i} \geqslant 0$ ) or by buying them back (if $K_{i} \leqslant 0$ ). Firm $i$ 's wealth becomes $w_{1}^{i}=w_{0}^{i}+K_{i}$.

- Stage 2: Each firm posts its own price and commits to sell any quantity at this price.

At stage 2, firms compete on price before the true cost is revealed by nature: the firm with the lowest price catches all the market, and must serve all the

\footnotetext{
${ }^{22}$ The impact of a multiplicative risk on the risk premium is ambiguous in general: an increase of market share corresponds to an increase in endowment decreasing the risk premium through the DARA hypothesis and an increase in risk, increasing the risk premium through the risk aversion hypothesis.
} 
demand that it faces; if several firms set the same lowest price, the market is equally shared among them. This price competition setting is similar to Wambach. ${ }^{1}$ Indeed price competition seems more natural than quantity competition if rationing the supply is difficult once the price of the product has been posted. ${ }^{23,15}$ Finally, the state of nature is realised: losses are revealed. The game is solved backward in the two following sections.

\section{Stage 2: price competition}

At the beginning of stage 2, each firm $i$ holds a level of capital $w_{1}^{i}$, the sum of its initial capital level and the external capital it raised: $w_{1}^{i}=w_{0}^{i}+K_{i}$. Formally, we denote these levels in a decreasing order $i=1, \ldots, n: w_{1}^{n}>w_{1}^{i}>w_{1}^{1}$. Under DARA, differences in the level of available capital lead to differences in the degree of risk aversion, which impact the price competition game. The less risk averse firm is the firm with the higher initial capital, that is firm $n$. At stage 2, firms compete on price with the objective to maximise their expected value $\mathbf{E} P\left(\tilde{w}_{f}^{i}\right)$. We have $\mathbf{E} P\left(\tilde{w}_{f}^{i}\right)=P\left(\bar{\pi}^{i}\left(p, q^{i}\right)-R\left(w_{1}^{i}+\bar{\pi}^{i}\left(p, q^{i}\right)\right.\right.$, $\left.q^{i}\right)$ where $\bar{\pi}^{i}\left(p, q^{i}\right)=$ $q^{i}(p-\bar{L})$ is the expected profit of firm $i . p$ is a symmetric Nash equilibrium if firms cannot increase their value by undercutting price. Formally

$$
\mathbf{E} P\left(w_{1}^{i}+\tilde{\pi}^{i}\left(p, \frac{Q(p)}{n}\right)\right) \geqslant \mathbf{E} P\left(w_{1}^{i}+\tilde{\pi}^{i}(p, Q(p))\right) .
$$

\section{Definition 1}

(1) We define $p_{i}^{\text {out }}$ as the price for which firm $i$ is indifferent between serving $1 / n$th of the market or its outside option $V^{\text {out: }}$

$$
\mathbf{E} P\left(w_{1}^{i}+\tilde{\pi}^{i}\left(p^{\text {out }}, \frac{Q\left(p^{\text {out }}\right)}{n}\right)\right)=V^{\text {out }} .
$$

We denote $p_{\max }^{\text {out }}=\max _{i=1, \ldots, n} p_{i}^{\text {out }}$.

(2) We define $p_{i}^{N}$ as the price for which firm $i$ is indifferent between serving the whole market and serving $1 / n$th of the market:

$$
\mathbf{E} P\left(w_{1}^{i}+\tilde{\pi}^{i}\left(p_{i}^{N}, \frac{Q\left(p_{i}^{N}\right)}{n}\right)\right)=\mathbf{E} P\left(w_{1}^{i}+\tilde{\pi}^{i}\left(p_{i}^{N}, Q\left(p_{i}^{N}\right)\right)\right) .
$$

We denote $p_{\min }^{N}=\min _{i=1, \ldots, n} p_{i}^{N}$.

\footnotetext{
${ }^{23}$ Rees et al., 1999.
} 
We have the following Lemma:

Lemma $1 \quad \partial p_{i}^{N} / \partial w_{1}^{i} \leqslant 0$.

Proof See the Appendix.

Thus when the level of firms' internal capital is high, that is firms are less risk averse, the competitive pressure they can exert is higher, and leads to a lower indifference price between serving the whole market and $1 / n$th of it.

The following proposition extends Wambach ${ }^{1}$ characterising the Nash equilibria of the price competition to asymmetric markets.

Proposition 1 In the case of asymmetric firms, if $p_{\max }^{\text {out }}<p_{\min }^{N}$.

(a) There exists a continuum $P^{N E}=\left[p_{\max }^{\text {out }}, p_{\min }^{N}\right]$ of Nash equilibrium prices $p \in P^{N E}$ for the n-oligopoly. ${ }^{24}$

(b) The maximum Nash price $p_{\min }^{N}$ corresponds to the indifference price for the less risk-averse firm between serving the whole market and serving $1 / n$th of it. $p_{\min }^{N}$ is higher than the competitive price, lower than the maximum monopoly price when it exists, and provides a value of the firm higher than her outside option.

\section{Proof See the Appendix.}

The fact that price competition across risk-averse firms leads to multiple equilibria has already been exhibited by Polborn ${ }^{10}$ and Wambach $^{1}$ in symmetric markets. In the present case, to the fundamental tradeoff between increasing expected profit and risk exposure must be added a wealth-effect term, which comes from the fact that the cost of bearing risk itself is a function of the value of expected profit. An equilibrium can be reached with asymmetrically capitalised firms. When the level of firms' internal capital is high, that is firms are less risk averse, the competitive pressure they can exert is then high, and leads to a lower maximum Nash price (Lemma 1). The firm with the highest level of internal capital thus defines the maximum Nash price. Note that the less capitalised the firm, the less oligopolistic rent it can extract.

\footnotetext{
${ }^{24}$ Note that in the case where $p_{\max }^{\text {out }}>p_{\min }^{N}$, the difference between the firms initial capital is such that the competitive pressure exerted by the less risk-averse firms $i$ leads to a situation where the most risk-averse firm cannot afford to stay in the market at such price. But the other firms $i$ can then still sustain the risk of all the market.
} 


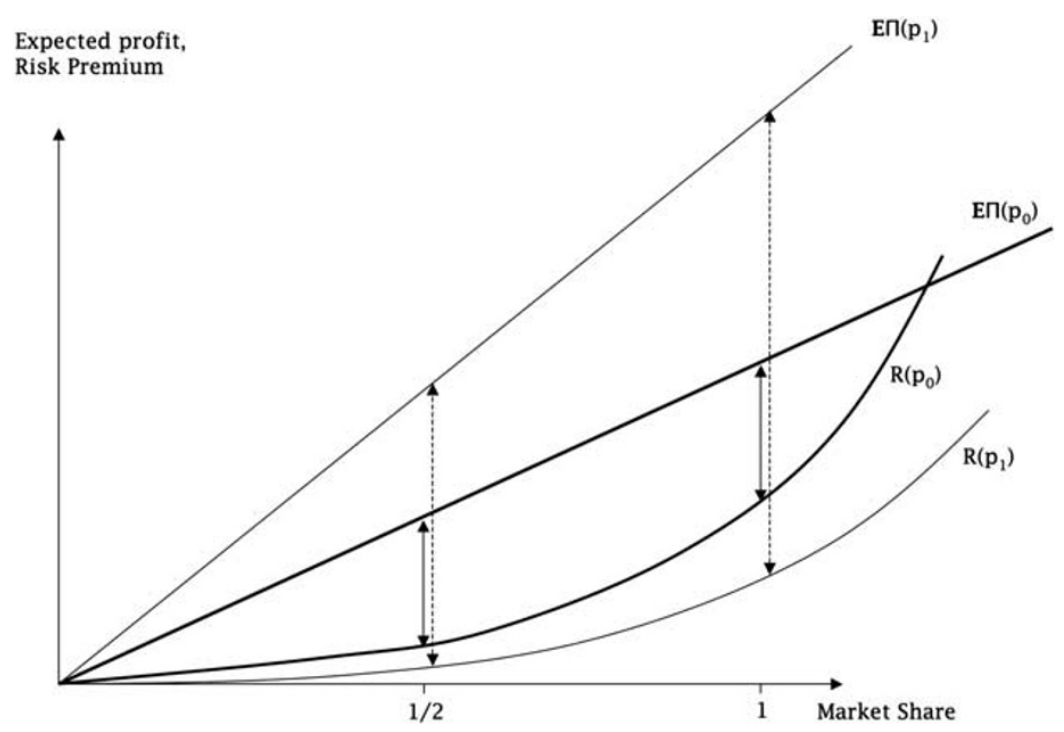

Figure 1. Characterisation of equilibrium prices for symmetric risk-averse firms competing on price case of inelastic demand.

We give on Figure 1 graphical interpretation of the results that enable to grasp the tradeoff at terms. To keep things simple, we consider the case of a duopoly with a perfectly inelastic demand equal to $Q$. Let $s^{i}=q^{i} / Q$ denote the market share of firm $i$. Both expected profit and pseudo-risk premium curves are drawn as a function of the market share for two (not necessarily Nash equilibria) prices: $p_{0}$ (thick line) and $p_{1}$ (thin line), with $p_{0}<p_{1}$. For a given price $p$, the expected profit of firm $i, s^{i} Q(p-\bar{L})$, is a linear function of the market share. The certainty equivalent of firm's wealth (represented by the vertical arrows) is the difference between the expected profit and the risk premium. For all market shares, the profits will be higher for $p_{1}$ than for $p_{0}$ but the risk premium is lower because of the wealth effect. Under DARA, this tends to decrease the firm's sensitivity to risk. Hence, for a given market share, an increase in price tends to increase the difference between the expected profit and the risk premium. Let us identify the Nash equilibrium prices. Start at price $p_{1}$. At this price, each firm has an incentive to slightly decreases its price in order to catch the whole market. At $p_{0}$, firms' values are equal at $Q / 2$ and $Q$. So when the indifference price, $p^{N}$ in our formal analysis is attained, no firm has an incentive to cut its price anymore. It is graphically straightforward that this price is not the single Nash equilibrium. 


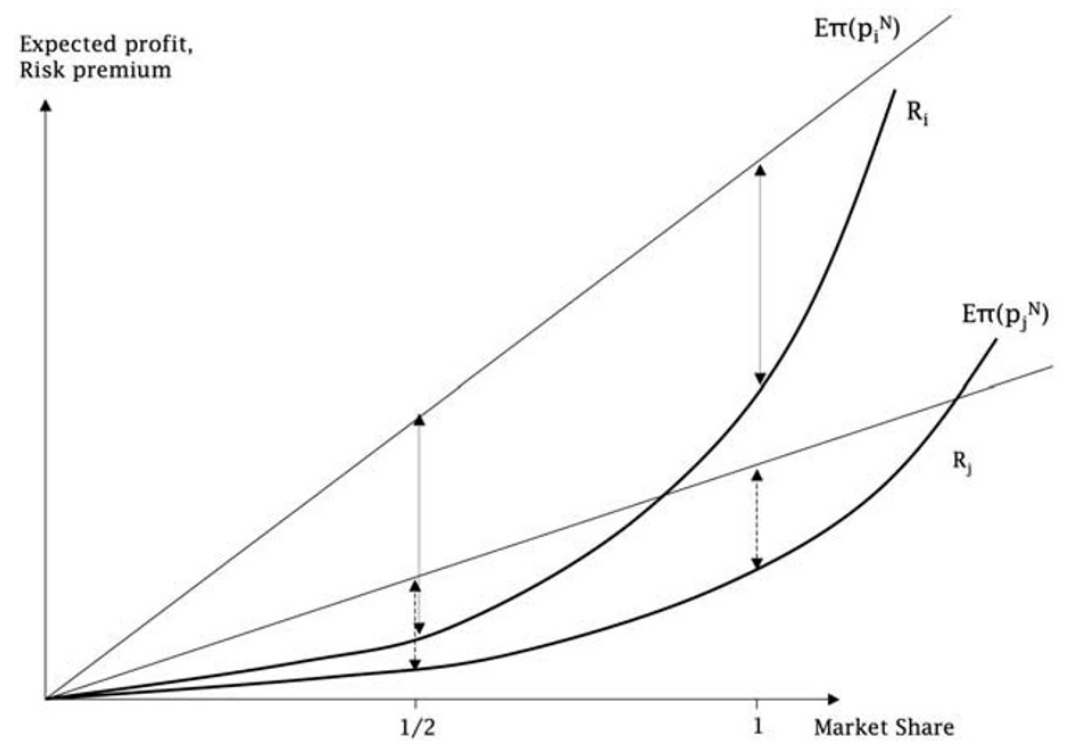

Figure 2. Characterisation of equilibrium prices for asymmetric risk-averse firms competing on price case of inelastic demand $-w_{1}^{j}>w_{1}^{i}$.

As long as firms get as much as their outside option, the firms participate to the market.

The case of asymmetric firms follows simply and is illustrated on Figure 2. Let us consider two firms $i, j$ where $w_{1}^{j}>w_{1}^{i}$ in the case of inelastic demand is considered. For a same level of coverage of the market, the risk premium of firm $i, R^{i}$ is higher than firm $j$ 's risk premium $R^{j}$. Both firms share the same expected profits. The risk premium curves correspond for each firm to the risk premium value for their indifference prices. Firm $i$ 's risk premium curves are always higher than firm $j$ 's. We can graphically see that the indifference price for firm $i$ is higher than for firm $j$. In the same manner, as in the symmetric case, there exists a continuum of Nash equilibrium prices $p$. The higher Nash equilibrium price $p_{j}^{N}$ corresponds to the indifference price for the less risk-averse firm, between serving the whole market and serving only one half of it.

Proposition 1's result on asymmetric markets is especially important in our two-stage setting since the anticipated Nash equilibrium price will be determinant for firms' choices of capital at stage 1. Using a payoff dominance argument, we select the price that maximises firms value, that is the maximum 
Nash price. ${ }^{25}$ We thus consider for the rest of the paper that the anticipated equilibrium price is $p_{\min }^{N}$ that we from now on denote $p^{N}$.

\section{Stage 1: capital choice}

\section{Equilibria characterisation}

At stage 1, firms non-cooperatively determine their levels of additional capital, $K_{i}$. We look for the Nash equilibria, that is a set of strategies $\left(K_{1}, \ldots, K_{n}\right)$ such that there is no profitable unilateral deviation for any firm. As the firm(s) with the highest level of internal capital determine(s) the market price $p^{N}\left(\max \left[K_{1}, \ldots, K_{n}\right]\right)$ while the competitors take the price as given, one must distinguish price-making and price-taking firms when studying the consequences of marginal deviations. ${ }^{26}$ The price-making firms take into account the strategic, product-market effect of their internal capital when choosing it, while price-taking firms do not. We define the objective function of the firms below.

Definition 2 The value of the firm net of capital, $V_{i}($.$) , is defined as follows:$

$$
\begin{aligned}
V_{i} & :\left(K_{1}, . ., K_{n}\right) \rightarrow P\left[w_{1}^{i}+\bar{\pi}\left(p^{N}(\bar{K})\right)-R\left(w_{1}^{i}+\bar{\pi}\left(p^{N}(\bar{K})\right), Q\left(p^{N}(\bar{K})\right)\right)\right] \\
& -(1+\tau) K_{i},
\end{aligned}
$$

where $\bar{K}=\max \left[\left(K_{1}, \ldots, K_{n}\right)\right] .^{27}$

For a price-making firm where $K_{i}=\bar{K}$, the anticipated Nash price is a function of $K_{i}$. Otherwise, for a price-taking firm, the anticipated Nash price only depends on an exogenous $\bar{K}$. To study the stage 1 subgame in more depth, the first step is to characterise the behaviour of $V_{i}($.$) , and the sign of a marginal$ deviation, in the symmetric case.

For a price-taking firm $i$, we have $\bar{K}=\max \left[K_{1}, \ldots, K_{n}\right]>K_{i}$. In the symmetric case, we are looking at the sign of the first-order derivative of $V_{i}$, for an

${ }^{25}$ In the model, we did not consider fixed setup cost to enter the market a cost that is sunk for firms already participating. In this case, a limit price argument could allow for the selection of a price. The equilibrium price would then have been the price that leads to the highest firm value in a Nash equilibrium with a no-entry constraint.

26 The following results are true for all anticipated strategies of equilibrium prices $p\left(K_{1}, \ldots, K_{n}\right)$ such that $\partial p^{N} / \partial w_{1} \leqslant 0$ (Lemma 1).

${ }^{27}$ The ex-ante value of the firm evaluated at $p^{N}$ is the same for serving a part of the market or the whole market. For the sake of simplicity, we work on the "whole market" expression. 
exogenous price equal to $p^{N}(\bar{K})$

$$
V_{i \text { Taker }}^{\prime}\left(K_{i}\right)=\underbrace{\left(1-R_{1}\right) P_{w}}_{M B}-\underbrace{(1+\tau)}_{M C_{\text {direct }}} .
$$

The first-order derivative formalises the tradeoff between the marginal cost of capital, $M C_{\text {direct }}$, and the marginal benefit of reducing the cost of risk for the firm, $M B$. If capital is not costly to hold, that is $\tau=0$, the first-order derivative becomes $\left(1-R_{1}\right) P_{w}-1$, which is always positive because by assumption $R_{1} \leqslant 0$ and $P_{w} \geqslant 1$.

For a price-making firm $i$, we have the $\bar{K}=\max \left[K_{1}, \ldots, K_{n}\right]=K_{i}$. The firstorder derivative of $V_{i}\left(K_{i}\right)$ is written as

$$
\begin{aligned}
V_{i \text { Leader }}^{\prime}\left(K_{i}\right)= & \underbrace{\left(1-R_{1}\right) P_{w}}_{M B} \\
& -\underbrace{\left[Q^{\prime}\left(p^{N}\right) R_{2}-\frac{\partial \bar{\pi}}{\partial p^{N}}\left(1-R_{1}\right)\right] \frac{\partial p^{N}}{\partial K_{i}} P_{w}}_{M C_{\text {strategic }}}-\underbrace{(1+\tau)}_{M C_{\text {direct }}} .
\end{aligned}
$$

When the firm $i$ is the most capitalised, it has to take into account the strategic effect due to product market competition $M C_{\text {strategic }}$ in addition to the direct cost-of-risk reduction incentive $M B$ and the marginal direct cost $M C_{\text {direct }}$ in its capital budgeting decision. This strategic effect represents a cost, as increasing internal capital reduces the market price set at stage 2 (Lemma 1). It is decomposed into two distinct terms that correspond to the following effects. The first one, the strategic wealth effect, is equal to

$$
M C_{\text {strat } W}\left(K_{i}\right)=-\frac{\partial p^{N}}{\partial K_{i}} \frac{\partial \bar{\pi}}{\partial p^{N}}\left(1-R_{1}\right) P_{w} .
$$

Indeed because of increased competitive pressure, the increase in expected final wealth due to more capital is partly counterbalanced by lower expected profits. If the price-making firm $i$ chooses its capital in a naive way, that is without considering this effect, it would overvalue its expected final wealth, and so the real cost of risk in its capital budgeting decision. The second term that we name strategic demand effect is equal to

$$
M C_{\text {strat } D}\left(K_{i}\right)=\frac{\partial p^{N}}{\partial K_{i}} Q^{\prime}\left(p^{N}\right) R_{2} P_{w} .
$$


It is null when the demand is price inelastic. By lowering the market price, a marginal increase in capital commits each firm to serve a higher demand, and so exposes them to a higher level of risk.

The question of the sign of both marginal deviations is important to understand the tradeoff of the players. We make the two following assumptions:

(A6a): $\forall K_{i}, V_{i}^{\prime \prime}$ Leader $\left(K_{i}\right) \leqslant 0$ and $\exists K_{i}^{*}: V_{i}^{\prime}$ Leader $\left(K_{i}^{*}\right)=0$.

(A6b): $\forall K_{i}, V_{i}^{\prime \prime}{ }_{\text {Taker }}\left(K_{i}\right) \leqslant 0$ and $\exists K_{i}^{+}: V_{i}^{\prime}$ Taker $\left(K_{i}^{+}\right)=0$.

(A6) makes the analysis tractable. $K_{i}^{*}$ defines the level of capital under which the price-making firm has interest to deviate by increasing its level of capital, whereas $K_{i}^{+}$defines the level above which the price-taking firm has interest to deviate by lowering its capital. Note that $V_{i}^{\prime}$ Leader $\left(K_{i}\right)=V_{i}^{\prime}$ Taker $\left(K_{i}\right)-M C_{\text {strategic }}$. It follows directly that $K_{i}^{*}<K_{i}^{+}$.

We place ourselves under assumption (A6) in the case of a symmetric oligopoly of $n$ firms, characterised by their initial wealth $w_{0}$. As firms are perfectly symmetric, for all $i, j K_{i}^{*}=K_{j}^{*}=K^{*}$ and $K_{i}^{+}=K_{j}^{+}=K^{+}$. We have the following proposition:

Proposition 2 Under (A6), if $w_{0}^{1}=\ldots=w_{0}^{n}=w_{0}$, there exists a continuum of symmetric equilibria $K_{1}=\ldots=K_{n}=K$ such that $K^{*} \leqslant K \leqslant K^{+}$.

Proof See the Appendix.

Figure 3 provides a graphical illustration of the continuum of Nash symmetric equilibria. The curve represents the net value function $V($.). The right-hand arrows correspond to the marginal net value of an increase of capital for a price-making firm, whereas the left-hand arrows show the marginal net value of a decrease of capital, for a price-taking firm. When $K<K^{*}$, a firm has no incentive to decrease capital as the marginal net value of being the follower is negative, whereas the marginal net value of increasing capital and being leader is positive. Thus, it is driven to $K=K^{*}$. For all $K$ between $K^{*}$ and $K^{+}$, the firm has no interest in increasing nor lowering its capital level as both would induce a lower net benefit (as taker or leader). For $K$ higher than $K^{+}$, however, there is no incentive for the firm to increase capital, but as a follower it has an interest in lowering her capital level as marginal net value for holding one more units of capital is too low compared with the cost of holding it. This leads to a continuum of Nash equilibrium of which one can select the set leading to the higher firm's value as in the case of the equilibrium price.

The case of asymmetric firms follows simply. To grasp the intuition of the game, consider 2 firms $l$ and $h$, with a low, respectively high, level of initial 


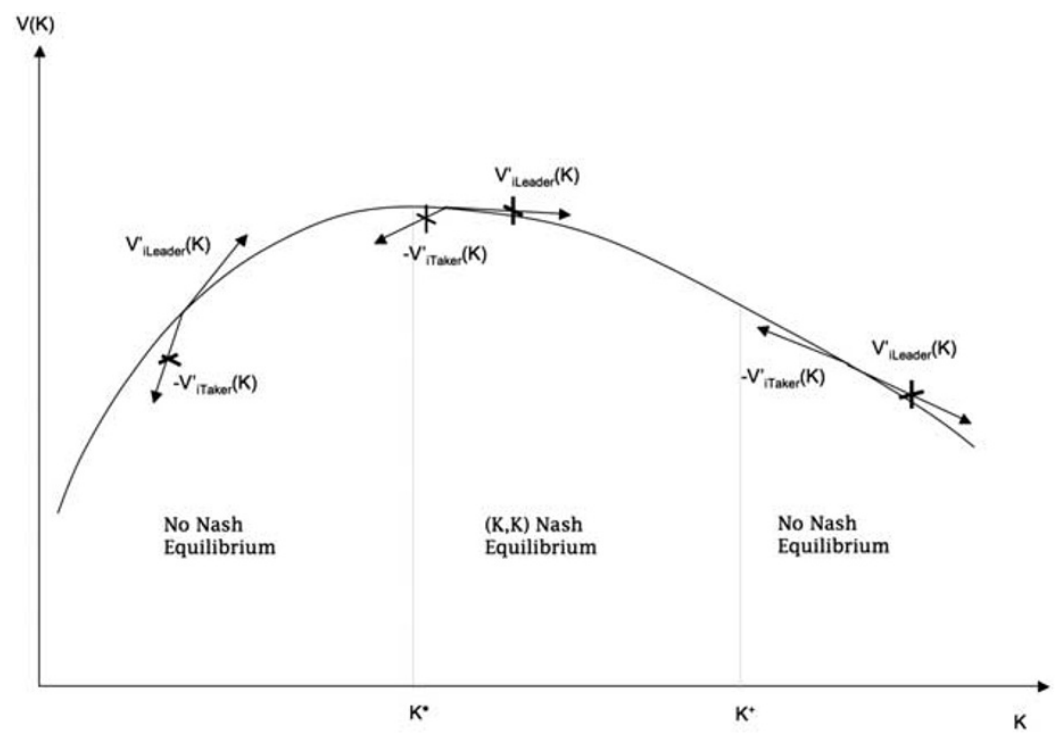

Figure 3. Equilibrium capital choices.

capital: $w_{0}^{l}<w_{0}^{h}$. First note that if assumption (A6a) holds for $V_{\text {ILeader }}$, it holds for $V_{h \text { Leader }}$ (see Appendix E). The firm with the lowest level of initial capital is the more risk averse. To have the same level of risk aversion, firm $l$ has to hold much more costly capital than firm $h$. As the cost of capital is linear, they will both obtain their maximal net value for the same level of wealth $\bar{w}=w_{0}^{l}+K_{l}^{*}=w_{0}^{h}+K_{h}^{*}$. As long as firm $l$ does not have the same amount of wealth as firm $h$, it has interest to hold the same total of capital, up to $K_{l}^{+}$, level at which it is too costly to hold capital.

Proposition 3 Under (A6), if $w_{0}^{1}<\ldots<w_{0}^{n}$, there exists a continuum of Nash equilibria $\left(K_{1}, \ldots, K_{n}\right)$, where $\forall i<n, K_{i}=K_{1}+w_{0}^{1}-w_{0}^{i}$, and $K_{1}^{*} \leqslant K_{1} \leqslant K_{1}^{+}$.

Proof See the Appendix.

For reasons similar to those developed to select the Nash equilibrium price, we focus on the level of capital that maximises firm's net value. Owing to its implicit definition, $K^{*}$ depends on the initial level of capital $w^{0}$. Intuitively a high level of initial capital could lead to a Nash equilibrium of no additional capital. Following Proposition 2, we can show that in this case, that is when $V_{i}^{\prime}(0)<0, K=0$ is a Nash equilibria. 


\section{Analysis of the results}

The model provides a framework with an endogenous choice of capital that accounts for specificities of the insurance market. It enhances the strategic role of capital in the product market competition of insurance firms. Indeed, firms have two different ways to manage risks. The first one is by acquiring more capital at first stage to lower their risk premium. The second one is by setting a higher price everything else being equal at the second stage. Both ways to hedge interact in a price competition setting. The opportunity cost of capital limits the amount of capital an insurance company may hold before subscription. A higher level of capital, however, induces a decrease in insurers' cost of risk. This allows for a more aggressive attitude on the market, a decrease in their equilibrium prices and thus an increase in the quantity insurers deliver. Hence, in the oligopoly context, the level of capital is limited by its strategic cost in addition to the cost of holding it.

The model allows for a double set of continuum of equilibrium: continuum of equilibrium prices at a fixed capacity, and continuum of sets of capital choices, when anticipating the maximum Nash price $p^{N}$. The selection of another price does not change the main logic of the results as long as the selected price decreases with the firm's wealth. Following the arguments developed previously we focus on the equilibrium extracting the highest rents for the firms, that is the set of $K^{*}$ and the equilibrium price $p^{N}$.

Corollary 1 Following a symmetric negative shock on initial wealth level, prices rise and global market capacity decreases.

The same results hold in the case of a positive shock on the cost of capital.

Proof The concavity of function $V_{i}($.$) leads to the result, derived from$ Proposition 2.

This result is interesting for the study of cycles. A high cost event in an industry with uncertainty on costs leads to a decrease of the capital available. In our framework, a lower initial capital leads to a lower level of capital (initial and external) at the end of stage 1, due to the cost of additional capital. The higher resulting price on the product market leads in the case of an elastic demand to a contraction of the industry's global capacity.

Note that in the preceding symmetric framework, a higher cost of capital leads to higher prices on the product market as capital is more costly to hold, and thus a contraction of the quantity supplied to the market in the case of elastic demand. An asymmetry in cost of capital for firms leads to interesting results. The firm with the lowest cost of capital chooses the level of capital that maximises her net value and leads the level of price on the market. The firms with the highest cost of 
98

capital follow her by choosing her level of capital depending on the price fixed by the other one. This result enhances the importance of the cost of capital as a strategic variable in the insurance industry.

An other interesting question, regarding the insurance industry, is the influence of the number of firms on capital choice and intensity of competition.

Corollary 2 Consider the n-firms oligopoly where the maximum initial wealth of the firms is noted $w_{M} \cdot p^{N}$ decreases with $\mathrm{n}$ when $w_{M}$ stays at the same level.

Proof See the Appendix.

This result is quite intuitive. Figure 4 illustrates this proposition in the case of inelastic demand. An increase in the number of reinsurer, for the same price, diminishes the surplus of the firm, as the quantity of the market served by the firm is lessened (from $1 / n$th to $1 / n+1$ th). Sharing the market between $n+1$ firms reduces the risk born by the companies and decreases the expected profits of the firms. However, owing to the scissors effect described previously, the maximum Nash equilibrium price $p_{n+1}^{N}$ for a market with $n+1$ firms is below the maximum Nash equilibrium price $p_{n}^{N}$ for a market

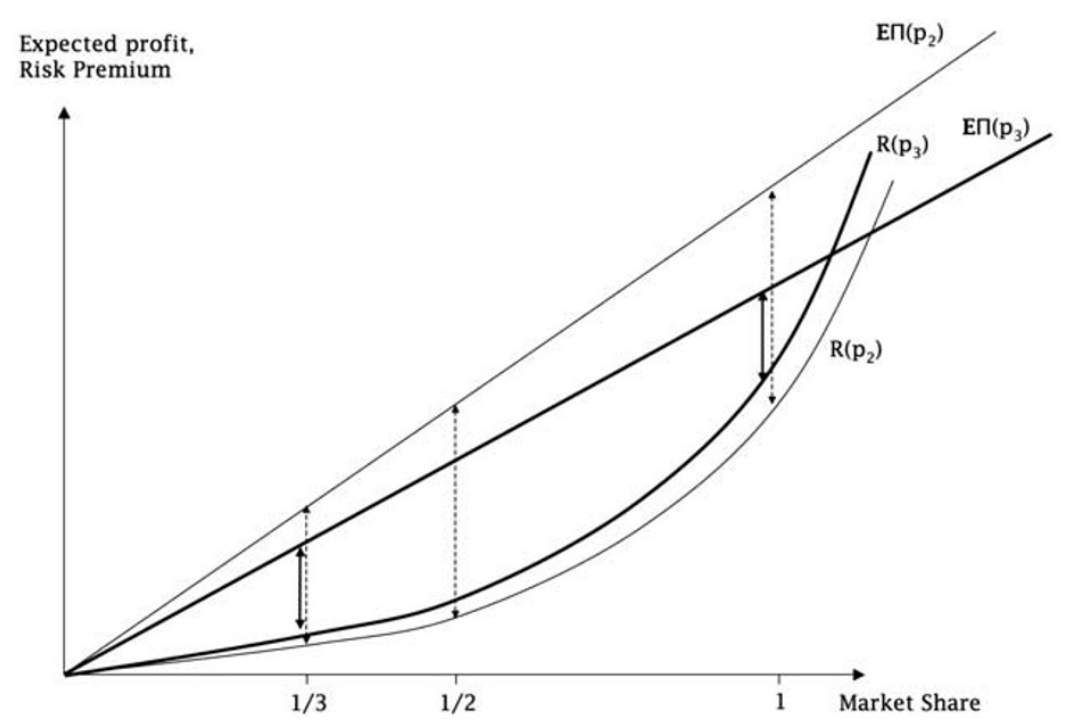

Figure 4. Maximum Nash prices, for a market of two symmetric firms and three symmetric firms case of inelastic demand. 
with $n$ firms. Thus, the higher the number of less risk-averse firms, the lower the market price.

\section{Social welfare and the need for capital regulation}

It is quite natural to consider now social welfare as the market comprises two imperfections on the product and the capital markets. In the insurance market, regulation is a key issue. Prices are seldom controlled except in the case of supply failure as for natural catastrophes in some countries or professional liability. Capital regulation is much more common and mainly justified in a solvency perspective. ${ }^{2,28}$ Here, we place ourselves in this second-best framework by supposing that government has direct control over the level of firms' capital but not on prices.

In the symmetric case, social welfare $S W$ is defined as the sum of consumer surplus $C S$ and firms' profits (i.e., the firms' values net of additional capital) with

$$
C S(p)=\int_{p}^{+\infty} Q(x) \mathrm{d} x
$$

The social welfare function is thus written as

$$
\begin{aligned}
S W(K, p)= & C S(p)+n\left(P \left[w_{0}+K+\bar{\pi}\right.\right. \\
& \left.\left.-R\left(w_{0}+K+\bar{\pi}, Q(p) / n\right)\right]-(1+\tau) K\right) .
\end{aligned}
$$

Proposition 4 Under assumption (A6), the level of capital $K^{g}$ that maximises social welfare is higher than $K^{*}$.

Proof If the benevolent and omniscient government only control $K$, then the first-order condition is

$$
\underbrace{\frac{\mathrm{d} p^{N}}{\mathrm{~d} K} Q^{\prime}\left(p^{N}\right)}_{T 1}+\underbrace{\frac{1}{n}\left(\left(1-R_{1}\right) P_{w}-\left[\frac{Q^{\prime}\left(p^{N}\right)}{n} R_{2}-\frac{\partial \bar{\pi}}{\partial p^{N}}\left(1-R_{1}\right)\right] \frac{\partial p^{N}}{\partial K} P_{w}-(1+\tau)\right)}_{T 2}=0 .
$$

\footnotetext{
${ }^{28}$ Note that it is equivalent for the government to control the price or on the level of capital as they both interact, when considering that firms anticipate the maximum Nash price. However, in the case of a continuum of equilibria, this may have a different signification.
} 
100

The marginal consumer surplus (T1) is positive. The second term (T2) is equal to 0 for $K=K^{*}$. Thus assuming $S W$ concave leads to $K^{g}>K^{*}$.

This result implies that imperfect competition combined with costly external capital leads to under-capitalisation in a social welfare perspective. Note that control of capital choice reduces the interval of equilibrium prices available at the second stage of the game. In our imperfect competition framework, higher capital requirements could lead to more competitive prices, as firms are less risk averse, and potentially to a better social welfare. However, stronger capital requirements can have an adverse effect as benefits realised on the product market do not compensate the cost of holding more capital.

It is interesting to point out that this model leads to a rationale for capital regulation due to imperfect competition, rather than standard solvency arguments. Indeed we do not take into account neither the value of the quality of the insurance companies for their customers nor the cost of solvency that is central for a regulation perspective in the financial intermediaries markets. In such case, there would be a tradeoff between competition issues and resilience of the market. In practice, the regulator must account for asymmetric information as well as uncertainty in many parameters. But it is important to enhance that capital regulation can impact positively the product market.

\section{Concluding remarks}

The paper extends Wambach's ${ }^{1}$ results as it considers a two-stage game: first firms choose their levels of capital then compete on price. Firms face the trade off between higher expected wealth and higher risk when expending their market shares, allowing for an endogenous rationale for raising more capital. We have shown the existence of a continuum of Nash equilibrium capital choices. Each level of capital leads to a continuum of Nash equilibrium prices of which we distinguish the one leading to firms' maximal value. Cost of capital as well as initial wealth levels of the firms has direct impacts on the market equilibrium prices.

Concerning the output price, our results are in line with the latest studies on the catastrophe reinsurance market that show that pricing far exceeds competitive pricing in excess of loss contracts. ${ }^{29}$ In our case, capital market imperfections as well as product market imperfections are integrated in the market price of risk. Furthermore, Froot and O'Connel1 ${ }^{14}$ have given evidence of the impact of the cost of capital on the pricing of risks in the reinsurance industry.

\footnotetext{
${ }^{29}$ Froot, 2001; Weiss and chung, 2004; Froot and O'Connell, 2008.
} 
Insofar we have considered a single strategic variable for stage 2, that is price. One wonders if our results are robust to a change, or an enlargement of the set of available strategies. ${ }^{30}$ Intuitively, if we consider quantity instead of price competition at stage 2 , the fundamental tradeoff between reducing risk and increasing competitive pressure, which determines the non-cooperative capital choice by firms, is still at work. Indeed, an increase in the level of capital reduces the firms' cost of risk and allows them to supply more "quantity" of insurance at stage 2. By increasing the aggregate supply of insurance, this leads at the market equilibrium to a lower price, which can be detrimental to the insurance firms. Oligopolistic rents would still be present, as well as a strategic effect of capital at stage one. The question of the uniqueness of such an equilibrium, at both stages, is still to be thoroughly answered.

Concerning price strategies, our model assumes away the fact that firms can limit the quantity they offer once the price is posted, whereas in the case of the insurance industry, the reinsurance (or retrocession) markets allow insurance companies to control the quantity of risk to which they are exposed. Reinsurance contracts could enter into the set of available mixed strategies. Two distinct aspects should be considered. First, introducing reinsurance allows firms to serve a higher demand as risk is shared, but on the other hand expected profits also decrease. In practice, it corresponds to the dual nature of reinsurance as both a "risk management and a financing decision." ${ }^{31,32}$ Second, there can also be imperfect competition at the reinsurance level, which raises the issue of the repartition of oligopoly rents at both levels. This is certainly an open question for future research.

One of the main features of the insurance industry is its cyclical behaviour, that links output price and capital depletion. In her review of insurance cycle literature, Weiss ${ }^{33}$ analyses the part of literature focused on "real cycles: shock theories and explanations for crises". In the literature, two basis models are used in the classical underwriting cycle theory: capacity constraint and risky debt hypothesis. Capital constraints were at first taken as exogenous, for a standard reason of regulation on the default risk as it is the case in Gron. ${ }^{8}$ Our model is related to a capacity constraint that emerges endogenously from the risk aversion of the firms combined with costly capital and is reinforced by the typical oligopolistic structure of the market. Despite the static nature of our model, it provides an implicit dynamic interpretation of capital

\footnotetext{
${ }^{30}$ Considering alternative strategy spaces can indeed have subtle consequences on the efficiency of the market as shown by Biais et al. (1998) in a risk trading context.

${ }^{31}$ Plantin, 2006.

${ }^{32}$ Reinsurance allows firms to reduce their cost of risk through risk sharing. In this sense, it is a substitute to capital holding except that it does not modify firms' cost of risk but risk itself.

${ }^{33}$ Weiss (2007).
} 
choice: internal capital choices of insurers at stage 1 can be interpreted as in Froot $^{6}$ as a "long-run target level of capital" whereas ex-post stochastic acquisition of capital exhibits increasing and convex adjustment costs.

Another explanation has been proposed to understand the endogenous nature of firms' capital choice. Zanjani ${ }^{34}$ considers risk neutral insurance companies that have limited liability. They face consumers that care for quality, and thus have incentives to hold costly capital. The firm is thus confronted with a quality/cost tradeoff and diversifies between the different lines of risk. In this case, capital requirements to maintain solvency have an impact on prices. In the same vein, it could be interesting to consider in our framework multiple lines of risk and the marginal impact of each on the level of long-term capital chosen by the firm.

Finally, the model provides a second-best rationale for capital regulation that relies on other arguments than solvency issues as classically social failure costs with limited liability issues. ${ }^{35}$ Imposing a minimal capital requirement reduces the interval of equilibrium prices. A regulation on capital can avoid situations in which firms are under-capitalised, leading to maximum Nash prices all the more high, and lower welfare. Capital regulation could then have a double impact: reduce firm insolvency as classically, but also enhance competition. The model thus underlines the importance of accounting for imperfect competition when assessing the impact of regulatory measures.

\section{Acknowledgements}

The authors thank Pierre Picard and Georges Dionne for interesting discussions. They thank Wamda Mimra, François Salanié, Jörgen Weibull, Jean-Marc Bourgeon, and Meglena Jeleva for helpful comments as well as two anonymous referees.

\section{References}

Asplund, M. (2002) 'Risk-averse firms in oligopoly', International Journal of Industrial Organization 20: 995-1012.

Biais, B., Foucault, T. and Salanié, F. (1998) 'Floors, dealer markets and limit order markets', Journal of Financial Markets 1(3-4): 253-284.

Brander, J.A. and Lewis, T.R. (1986) 'Oligopoly and financial structure: The limited liability effect', American Economic Review 76(5): 956-970.

Fagart, M.C., Fombaron, N. and Jeleva, M. (2002) 'Risk mutualization and competition in insurance markets', The Geneva Papers on Risk and Insurance - Theory 27(2): 115-141.

Froot, K.A. (2001) 'The market for catastrophe risk: A clinical examination', Journal of Financial Economics 60(2-3): 529-571.

\footnotetext{
34 Zanjani (2002).

35 Matutes and Vives, 2000.
} 
Froot, K.A. (2007) 'Risk management, capital budgeting, and capital structure policy for insurers and reinsurers', The Journal of Risk and Insurance 74(2): 273-299.

Froot, K.A. and O'Connell, P.G.J. (2008) 'On the pricing of intermediated risks: Theory and application to catastrophe reinsurance', Journal of Banking \& Finance 32(1): 69-85.

Froot, K.A., Scharfstein, D.S. and Stein, J.C. (1993) 'Risk management: Coordinating corporate investment and financing policies', The Journal of Finance 48(5): 1629-1658.

Gollier, C. (2001) The Economics of Risk and Time, Cambridge, MA: MIT Press.

Gollier, C. (2007) The determinants of the insurance demand by firms, Working Paper.

Gron, A. (1990) 'Property-casualty insurance cycles, capacity constraints and empirical results', $\mathrm{PhD}$ thesis, MIT.

Kreps, D.M. and Scheinkman, J.A. (1983) 'Quantity precommitment and bertrand competition yield cournot outcomes', The Bell Journal of Economics 14(2): 326-337.

Matutes, C. and Vives, X. (2000) 'Imperfect competition, risk taking, and regulation in banking', European Economic Review 44(1): 1-34.

Nye, B.F. and Hofflander, A.E. (1987) 'Economics of oligopoly: Medical malpractice insurance as a classic illustration', The Journal of Risk and Insurance 54(3): 502-519.

Plantin, G. (2006) 'Does reinsurance need reinsurers?' The Journal of Risk and Insurance 73(1): 153-168.

Plantin, G. and Rochet, J.-C. (2007) When Insurers Go Burst, Princeton, NJ: Princeton University Press.

Polborn, M.K. (1998) 'A model of an oligopoly in an insurance market', The Geneva Papers on Risk and Insurance - Theory 23(1): 41-48.

Rees, R., Gravelle, H. and Wambach, A. (1999) 'Regulation of insurance markets', The Geneva Papers on Risk and Insurance - Theory 24: 55-68.

Tirole, J. (1988) The Theory of Industrial Organization, Cambridge, MA: MIT Press.

Tirole, J. (2006) The Theory of Corporate Finance, Princeton, NJ: Princeton University Press.

Vives, X. (1999) Oligopoly Pricing: Old Ideas and New Tools, Cambridge, MA: MIT Press.

Wambach, A. (1999) 'Bertrand competition under cost uncertainty', International Journal of Industrial Organization 17: 941-951.

Wanzenried, G. (2003) 'Capital structure decisions and output market competition under demand uncertainty', International Journal of Industrial Organization 21: 171-200.

Weibull, J.W. (2006) Price competition and convex costs, Working Paper.

Weiss, M.A. (2007) 'Underwriting cycles: A synthesis and further direction', Journal of Insurance Issues 30(1): 31-45.

Weiss, M.A. and Chung, J.-H. (2004) 'U.S. reinsurance prices, financial quality, and global capacity', Journal of Risk \& Insurance 71(3): 437-467.

Zanjani, G. (2002) 'Pricing and capital allocation in catastrophe insurance', Journal of Financial Economics 65(2): 283-305.

\section{About the Authors}

Julien Hardelin holds a PhD in Economics from the École Polytechnique. He received a Master's degree in Environmental and Resource Economics from AgroParisTech-ENGREF, and a Master's degree in Agronomy and Environment from AgroParisTech.

Sabine Lemoyne de Forges holds a $\mathrm{PhD}$ in Economics from the École Polytechnique. She received a Master's degree in Environmental and Resource Economics from AgroParisTech-ENGREF. 
104

\section{Appendix A}

\section{Proof of Lemma 1}

Let us consider $n$ firms with different levels of internal capital, and among them firm $i$ and firm $j$ such that $w_{1}^{j}>w_{1}^{i}$. As $p_{i}^{N}$ is the indifference price for firm $i$ for serving the whole market or $1 / n$th of it, then $\mathbf{E} P\left(w_{1}^{i}+\tilde{\pi}_{i}\left(p_{i}^{N},\left(Q\left(p_{i}^{N}\right)\right) / n\right)\right)=$ $\mathbf{E} P\left(w_{1}^{i}+\tilde{\pi}^{i}\left(p_{i}^{N}, Q\left(p_{i}^{N}\right)\right)\right)$. As $P$ is strictly increasing, this is equivalent for $i, j$ to

$$
\begin{gathered}
\bar{\pi}\left(p_{i}^{N}, Q\left(p_{i}^{N}\right) / n\right)-R\left(w_{1}^{i}+\bar{\pi} \times\left(p_{i}^{N}, Q\left(p_{i}^{N}\right) / n\right), Q\left(p_{i}^{N}\right) / n\right) \\
=\bar{\pi}\left(p_{i}^{N}, Q\left(p_{i}^{N}\right)\right)-R\left(w_{1}^{i}+\bar{\pi}\left(p_{i}^{N}, Q\left(p_{i}^{N}\right)\right), Q\left(p_{i}^{N}\right)\right) .
\end{gathered}
$$

Let us compare at price $p_{i}^{N}$ the expected value of firm $j$ for serving the whole market and $1 / n$th of it. Assumption (A5) leads to

$$
\begin{aligned}
R\left(w_{1}^{j}+\right. & \left.\bar{\pi}\left(p_{i}^{N}, Q\left(p_{i}^{N}\right) / n\right), Q\left(p_{i}^{N}\right) / n\right) \\
& -R\left(w_{1}^{j}+\bar{\pi}\left(p_{i}^{N}, Q\left(p_{i}^{N}\right)\right), Q\left(p_{i}^{N}\right)\right)> \\
R\left(w_{1}^{i}+\right. & \left.\bar{\pi}\left(p_{i}^{N}, Q\left(p_{i}^{N}\right) / n\right), Q\left(p_{i}^{N}\right) / n\right) \\
& -R\left(w_{1}^{i}+\bar{\pi}\left(p_{i}^{N}, Q\left(p_{i}^{N}\right)\right), Q\left(p_{i}^{N}\right)\right) .
\end{aligned}
$$

Using Equation (9):

$$
\begin{aligned}
R\left(w_{1}^{j}+\right. & \left.\bar{\pi}\left(p_{i}^{N}, Q\left(p_{i}^{N}\right) / n\right), Q\left(p_{i}^{N}\right) / n\right) \\
- & R\left(w_{1}^{j}+\bar{\pi}\left(p_{i}^{N}, Q\left(p_{i}^{N}\right)\right), Q\left(p_{i}^{N}\right)\right)> \\
& \bar{\pi}\left(p_{i}^{N}, Q\left(p_{i}^{N}\right) / n\right)-\bar{\pi}\left(p_{i}^{N}, Q\left(p_{i}^{N}\right)\right) .
\end{aligned}
$$

Thus

$$
\begin{aligned}
& \bar{\pi}\left(p_{i}^{N}, Q\left(p_{i}^{N}\right)\right)-R\left(w_{1}^{j}+\bar{\pi}\left(p_{i}^{N}, Q\left(p_{i}^{N}\right)\right), Q\left(p_{i}^{N}\right)\right)> \\
& \bar{\pi}\left(p_{i}^{N}, Q\left(p_{i}^{N}\right) / n\right)-R\left(w_{1}^{j}+\bar{\pi}\left(p_{i}^{N}, Q\left(p_{i}^{N}\right) / n\right) .\right.
\end{aligned}
$$

And as $P$ is strictly increasing, the expected value to cover the whole market is higher than the expected value to cover $1 / n$th of it. Thus, the indifference price is lower for the less risk-averse firm, that is the firm with higher level of initial capital.

Thus under assumptions (A1), (A2), and (A5), in the case of symmetric firms, $w_{1}^{j}>w_{1}^{i} \Rightarrow p_{i}^{N}>p_{j}^{N}$. Equation (9) implicitly defining $p_{i}^{N}$ allows for the continuity of $p_{i}^{N}$ compared with $w_{1}$. Thus $\partial p_{i}^{N} / \partial w_{1} \leqslant 0$. 


\section{Appendix B}

\section{Proof of Proposition 1}

\section{Case of symmetric firms}

Lemma 2 (Wambach): Under assumptions (A1) and (A3), if there is a price in the market such that the $\mathrm{n}$ firms have a value equal to their outside option, the value of any firm serving the whole market at this price is strictly smaller, formally:

$$
\mathbf{E} P\left(w_{1}^{i}+\tilde{\pi}^{i}(p, Q / n)\right)=V^{\text {out }} \Rightarrow \mathbf{E} P\left(w_{1}^{i}+\tilde{\pi}^{i}(p, Q)\right)<V^{\text {out }} .
$$

\section{Proof See Wambach ${ }^{1}$ for proof.}

Lemma 2 leads to $p \in P^{N E}$ if and only if $\mathbf{E} P\left(w_{1}^{i}+\tilde{\pi}^{i}(p,(Q(p)) / n)\right) \geqslant \mathbf{E} P\left(w_{1}^{i}+\tilde{\pi}^{i}(p, Q(p))\right)$ that is equivalent to $p \in P^{N E}$ if and only if $p \in\left[p^{\text {out }}, p^{N}\right]$. Indeed, let us consider a deviation of firm $i$ when all firms set a common price $p \in P^{N E}$. If $i$ raises her price, then it obtains no demand, as all the residuals firms meet the demand. If $i$ lowers its price, its serves the whole market, and decreases its profit. As $P$ is concave, we have

$$
\frac{d^{2}}{d q^{i 2}} \mathbf{E} P\left(w_{1}^{i}+\tilde{\pi}^{i}\left(p, q^{i}\right)\right)=\mathbf{E}\left((p-\tilde{L})^{2} P_{w w}\left(w_{1}^{i}+\tilde{\pi}^{i}\left(p, q^{i}\right)\right)\right)<0 .
$$

As $p^{N}$ verifies $\mathbf{E} P\left(w_{1}^{i}+\tilde{\pi}^{i}\left(p^{N},\left(Q\left(p^{N}\right)\right) / n\right)\right)=\mathbf{E} P\left(w_{1}^{i}+\tilde{\pi}^{i}\left(p^{N}, Q\left(p^{N}\right)\right)\right)$, a price-taker firm has an optimal output between $(Q(p)) / n$ and $Q$. From (A4), we directly obtain that the competitive price is lower than $p^{N}$. Let us consider $p \in P^{N E}$. As $\left.p^{\text {out }}=\min \left(p^{N E}\right), \mathbf{E} P\left(w_{1}^{i}+\tilde{\pi}^{I}\left(P^{\text {out }},\left(Q\left(p^{\text {out }}\right)\right) / n\right)\right)\right)=V^{\text {out }}$. From (A3), we obtain $\mathbf{E} P\left(w_{1}^{i}+\tilde{\pi}^{i}\left(p^{N},\left(Q\left(p^{N}\right)\right) / n\right)\right)>V^{\text {out }}$. Thus, the value of the firms at $p^{N}$ is higher than their outside option.

Finally, we need the following lemma to prove that $p^{N}$ is lower than the maximal monopoly price $p^{m}$.

\section{Lemma 3}

$$
\left.P^{N E} \cap\right] p^{m},+\infty[=\emptyset \text {. }
$$

Proof (Weibull provides a similar proof in the case of convex costs of production): Let us suppose that all firms price at $p \in P^{N E}$, with $p>p^{m}$. Firm $i$ has a demand $q^{i}<Q(p)$. As $Q(p)$ is continuous and $\lim _{p \rightarrow+\infty} Q(P)=0$.

$$
\exists p^{*}>p: Q\left(p^{*}\right)=q^{i}
$$


106

$$
\mathbf{E} P\left(w_{1}^{i}+\left(p^{*}-\tilde{L}\right) Q\left(p^{*}\right)\right)=\mathbf{E} P\left(w_{1}^{i}+\left(p^{*}-\tilde{L}\right) q^{i}\right)>\mathbf{E} P\left(w_{1}^{i}+(p-\tilde{L}) q^{i}\right) .
$$

By definition, as $p^{m}$ is the optimal monopoly price, $\mathbf{E} P\left(w_{1}^{i}+\left(p^{m}-\tilde{L}\right) \times Q\left(p^{m}\right)\right)>$ $\left.\mathbf{E} P\left(w_{1}^{i}+p^{*}-\tilde{L}\right) Q\left(p^{*}\right)\right)$

$$
\mathbf{E} P\left(w_{1}^{i}+\left(p^{m}-\tilde{L}\right) Q\left(p^{m}\right)\right)>\mathbf{E} P\left(w_{1}^{i}+(p-\tilde{L}) q^{i}\right) .
$$

As $p>p^{m}$, thus the firm $i$ can unilaterally deviate and enhance its value. Thus $p$ is not a Nash equilibrium.

Case of asymmetric firms

In the case where $p_{\max }^{\text {out }}<p_{\min }^{N}$, Lemma 1 leads to $p \in P^{N E}$ if and only if $\mathbf{E} P\left(w_{1}^{i}+\tilde{\pi}^{i}(p,(Q(p)) / n)\right) \geqslant \mathbf{E} P\left(w_{1}^{i}+\tilde{\pi}^{i}(p, Q(p))\right)$ that is equivalent to $p \in P^{N E}$ if and only if $p \in\left[p_{\max }^{\text {out }}, p_{\min }^{N}\right]$. Let us suppose that $p>p_{\min }^{N}$. The firm $j$ that has the minimum Nash price $p_{\min }^{N}$ may lower the price and then catch the whole market. Thus $p$ is not a Nash equilibrium. Then let us consider a deviation of firm $i$ when all firms set a common price $p \in P^{N E}$. If $i$ raises its price, then it obtains no demand, as all the residuals firms meet the demand. If $i$ lowers its price, it serves the whole market, and decreases its profit. $p$ defines then a Nash equilibrium. The extension to an oligopoly of $n$ firms is immediate and when $p_{\max }^{\text {out }}>p_{\min }^{N}$.

However, other Nash equilibrium may exist that consider less firms. In fact, for $p<p_{\max }^{\text {out }}$, only $n-1$ firms stay on the market. Let us define for the remaining firms $p_{\max }^{n-1}$ the maximum of the prices for which the firms are indifferent between serving $1 / n-1$ th of the market or their outside option. If $p_{\max }^{n-1}<p_{\max }^{\text {out }}$, there still exists a continuum of equilibrium prices for a $n-1$ oligopoly. For $m=1, \ldots, n-1$, we define for the $m$ firms remaining in the market

$$
\begin{aligned}
p_{\max }^{m} & =\max _{i=1 . . m}\left\{p_{i}^{\text {out }}: \mathbf{E} P\left(w_{1}^{i}+\tilde{\pi}^{i}(p, Q(p) / m)\right)\right. \\
& \left.=\mathbf{E} P\left(w_{1}^{i}+\tilde{\pi}^{i}(p, Q(p))\right)\right\} .
\end{aligned}
$$

We note the following interval, that may be empty:

$$
I^{m}=\left[p_{\max }^{m} ; \max _{i=m+1 . . n}\left\{p_{\max }^{m}\right\}[.\right.
$$

When assumptions (A1)-(A5) hold, in the case of non-symmetric firms that differs by their risk aversion, there exist submarkets price equilibrium intervals $I^{m}$ for each $m$-oligopoly. 


\section{Appendix C}

\section{Proof of Proposition 2}

Consider an unilateral deviations of a firm $i$ in the case of an $n$ oligopoly of symmetric firms from the symmetric Nash equilibrium candidate $(\bar{K}, \bar{K})$. Under assumption (A6), we only need to look at marginal deviations. We first note that

$$
V_{i \text { Taker }}^{\prime}\left(K_{i}\right)=V_{i \text { Leader }}^{\prime}\left(K_{i}\right)+M C_{\text {strat } W}\left(K_{i}\right)+M C_{\text {strat } D}\left(K_{i}\right)
$$

Increasing capital: $K_{i}>\bar{K}$

If firm $i$ chooses to increase its level of capital form the symmetric situation, it becomes the leader of the game, thus determines the market price $p^{N}\left(K_{i}\right)$. Considering assumption (A6):

- $\forall \bar{K}<K^{*}, V_{i \text { Leader }}^{\prime}(\bar{K})>0$. Hence $\bar{K}<K^{*}$ cannot be a Nash equilibrium.

- $\forall \bar{K} \geqslant K^{*}, V_{i \text { Leader }}^{\prime}(\bar{K}) \leqslant 0$. Hence all $\bar{K} \geqslant K^{*}$ are candidates to be a Nash equilibrium.

Decreasing capital: $K_{i}<\bar{K}$

If firm $i$ chooses a lower level of capital than the other firms then the market price remains equal to $p^{N}(\bar{K})$, which is determined by the more capitalized firms. Considering the previous discussion:

- $\forall \bar{K}<K^{*},-V_{i \text { Taker }}^{\prime}(\bar{K})=-V^{\prime}{ }_{i \text { Leader }}(\bar{K})-M C_{\text {start } W}(\bar{K})-M C_{\text {start } D}(\bar{K}) \leqslant 0$, hence a marginal decrease in capital is not profitable.

- $\forall K^{+} \geqslant \bar{K} \geqslant K^{*},-V_{i \text { Taker }}^{\prime}(\bar{K})=-M B(\bar{K})+M C_{\text {direct }}(\bar{K}) \leqslant 0$ following assumption (A6b).

- $\forall K^{+} \geqslant \bar{K},-V_{i \text { Taker }}^{\prime}(\bar{K})=-M B(\bar{K})+M C_{\text {direct }}(\bar{K}) \geqslant 0$ thus a marginal decrease of capital is unilaterally profitable.

We thus conclude that the symmetric couples of capital $(\bar{K}, \bar{K})$ are a Nash equilibrium for $K^{*} \leqslant \bar{K} \leqslant K^{+}$.

\section{Appendix D}

\section{Proof of Proposition 3}

Consider 2 firms $l$ and $h$, with a low and high, respectively, level of initial capital: $w_{0}^{l}<w_{0}^{h}$. If $V_{l \text { Leader }}$ follows assumption (A6a), then $V_{l \text { Leader }}^{\prime}$ is decreasing. For all $K_{l}$, let us define $K_{h}$ such that $w_{0}^{l}+K_{l}=w_{0}^{h}+K_{h}, K_{h}<K_{l}$. Thus $V_{h \text { Leader }}^{\prime}\left(K_{h}\right)=V_{l \text { Leader }}^{\prime}\left(K_{l}+w_{0}^{l}-w_{0}^{h}\right)$ is also decreasing in $K_{h}$. And $V_{h \text { Leader }}$ follows assumption (A6a). Both firms reach their maximum net value (for leader) for the same level of capital $w_{0}^{l}+K_{l}^{*}=w_{0}^{h}+K_{h}^{*}$ where $K_{h}^{*}<K_{i}^{*}$. 
We use the same logic as in the proof of Proposition 2. Consider firm $h$. For all $K_{h} \leqslant K_{h}^{*}$, firm $h$ when being the leading firm has the interest for increasing its level of external capital. In this situation, firm $l$ has always interest to increase as well its level of external capital up to $K_{l}^{*}$, where the Nash price is $p^{N}\left(w_{0}^{h}+K_{h}^{*}\right)$.

For all $K_{h}^{*} \leqslant K_{h} \leqslant K_{h}^{+}$, firm $h$, as the leading firm, has no interest to increase its level of external capital, neither has it interest to lower it when being a pricetaking firm. For all $K_{l}^{*} \leqslant K_{l} \leqslant K_{l}^{+}$, firm $l$ as the leading firm has no interest to any deviation, when $w_{0}^{l}+K_{l}=w_{0}^{h}+K_{h}$.

Let us note $K_{h}^{M}: w_{0}^{l}+K_{l}^{+}=w_{0}^{h}+K_{h}^{M}$. For all $K_{h}>K_{h}^{M}$, firm $h$ is the leading firm, as it is less risk averse. $l$ chooses the level of external capital maximizing its net value as a follower, $K<K_{l}^{+}$, and firm $h$ thus benefits from lowering its level of capital. So for all $K_{h}>K_{h}^{M}$, there is no Nash equilibrium.

\section{Appendix E}

\section{Proof of Corollary 2}

We provide the proof of the corollary for the case of $n$ symmetric firms. We consider $n+1$ firms with the same initial wealth $w_{1}$ that compete on price. We note $p_{n}^{N}$ the maximum Nash price of the competition of $n$ of these firms, and $p_{n+1}^{N}$ the maximum Nash price for $n+1$ firms. By definition

$$
\mathbf{E} P\left(w_{1}^{i}+\tilde{\pi}^{i}\left(p_{n}^{N}, \frac{Q\left(p_{n}^{N}\right)}{n}\right)\right)=\mathbf{E} P\left(w_{1}^{i}+\tilde{\pi}_{i}\left(p_{n}^{N}, Q\right)\right),
$$

that is $\mathbf{E} P\left(w_{1}^{i}+(1 / n)\left(p_{n}^{N}-\tilde{L}\right) Q\left(p_{n}^{N}\right)\right)=\mathbf{E} P\left(w_{1}^{i}+\left(p_{n}^{N}-\tilde{L}\right) Q\left(p_{n}^{N}\right)\right)$.

Let us consider a multiplicative factor of risk $\lambda . \mathbf{E} P\left(w_{1}^{i}+\lambda\left(p_{n}^{N}-\tilde{L}\right) Q\left(p_{n}^{N}\right)\right)$ is a concave function of $\lambda$.

Then, as $(1 /(n+1))<1 / n<1$

$$
\mathbf{E} P\left(w_{1}^{i}+\frac{1}{n+1} \tilde{\pi}^{i}\left(p_{n}^{N}, Q\left(p_{n}^{N}\right)\right)\right)<\mathbf{E} P \times\left(w_{1}^{i}+\tilde{\pi}_{i}\left(p_{n}^{N}, Q\left(p_{n}^{N}\right)\right)\right) .
$$

Thus all firms prefer serving the whole market to $(n+1)$ th of it at $p_{n}^{N}$. As all functions are continuous, a small decrease in price will not violate the condition of equilibrium for a market with $n+1$ symmetric firms that is $\mathbf{E} P\left(w_{1}^{i}+\tilde{\pi}^{i}\left(p_{n+1}^{N},\left(Q\left(p_{n+1}^{N}\right) /(n+1)\right)\right)\right)=\mathbf{E} P\left(w_{1}^{i}+\tilde{\pi}_{i}\left(p_{n+1}^{N}, Q\right)\right)$. Thus, using (A3), $p_{n+1}^{N}<p_{n}^{N}$. 